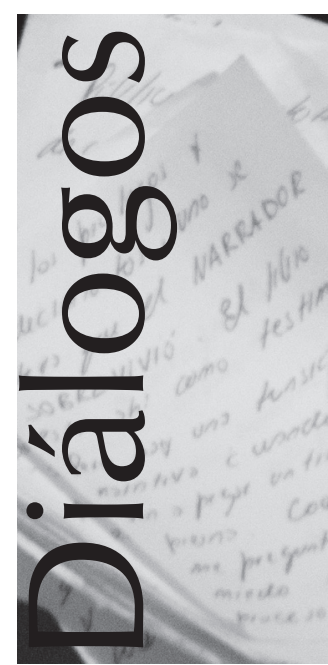

\title{
Aborto, sororidad y autonomía de los cuerpos: diálogo con la diputada nacional Mónica Macha
}

\author{
Abortion, sorority and body autonomy: \\ a conversation with Mónica Macha, \\ representative in the Argentine Chamber of \\ Deputies
}

Dora Barrancos ${ }^{1}$, Patricia Rosemberg ${ }^{2}$

RESUMEN Días después de la aprobación en la cámara de diputados del proyecto de ley de Interrupción Voluntaria del Embarazo, Salud Colectiva convocó a Dora Barrancos y Patricia Rosemberg para dialogar con la diputada nacional Mónica Macha sobre los sucesos previos a la media sanción del proyecto. En la charla surgieron otras temáticas, que inundaron las calles de todo el país durante todo el año. Las tres recuperan la militancia y la sororidad dentro y fuera del recinto, el protagonismo de la juventud, "la revolución de las hijas", la discusión sobre la autonomía de los cuerpos, el rol de los médicos y cómo todo esto devino en un cambio cultural del que ya no hay vuelta atrás. Esta charla relata un momento histórico, en palabras de algunas de sus protagonistas.

PALABRAS CLAVES Derechos de la Mujer; Feminismo; Aborto Legal; Legislación; Argentina.

ABSTRACT Just days after the Argentine Chamber of Deputies approved the bill on the Voluntary Termination of Pregnancy, Salud Colectiva asked Dora Barrancos and Patricia Rosemberg to converse with representative Mónica Macha regarding the events leading up to the Chamber's approval of the bill. In the conversation other themes emerged in connection to the energy that flooded the streets all over the country throughout the year. The three women highlighted the activism and sorority present inside and outside of the chamber, the central role of youth, "the revolution of the daughters," the discussion of body autonomy, the role of doctors and how the struggle became a cultural change from which there is no return. This conversation narrates a historical moment in the words of some of its actors.

KEY WORDS Women's Rights; Feminism; Legal Abortion; Legislation; Argentina.

${ }^{1}$ Socióloga, Doctora en Historia. Ex directora, Instituto Interdisciplinario de Estudios de Género, Facultad de Filosofía y Letras, Universidad de Buenos Aires, Argentina. $\square$

${ }^{2}$ Médica. Ex directora de la Maternidad de Moreno Estela de Carlotto; Directora de Maternidad e Infancia, Hospital Emilio Zerboni. Estudiante, Doctorado en Salud Colectiva, Instituto de Salud Colectiva, Universidad Nacional de Lanús, Argentina. $\triangle$ iD 


\section{INTRODUCCIÓN}

Esta entrevista fue realizada pocos días después de que una marea de pañuelos verdes colmara las inmediaciones del Congreso de la Nación. Esa "ola verde", en clara analogía con las "olas" del feminismo, tendría en este caso un objetivo concreto: la legalización del aborto en Argentina. El miércoles 13 de junio de 2018, el Proyecto de Ley sobre Interrupción Voluntaria del Embarazo llegaba finalmente a la Cámara de Diputados, después de dos meses de audiencias públicas en comisiones. Fue un día histórico en todo el país, en el que millones de mujeres y personas con capacidad de gestar tomaron la calle y pasaron toda la noche en vigilia a la espera de la votación en la Cámara de Diputados. La mañana del 14 de junio, después de veintidós horas de sesión, la noticia de que el proyecto de ley había sido aprobado con 129 votos a favor, 125 en contra y una abstención, produjo un estallido de abrazos, lágrimas y emociones que traspasaron las fronteras y fueron retomados por los movimientos feministas de América Latina.

Desde 2007, el proyecto fue presentado seis veces por la Campaña Nacional por el Derecho al Aborto Legal, Seguro y Gratuito, que actualmente está conformada por un amplio espectro de organizaciones políticas, grupos y personalidades vinculadas al movimiento de mujeres, trabajadores de la salud, sindicatos, organismos de derechos humanos, personas del ámbito académico y científico, y diversos movimientos sociales y culturales. La Campaña nace en 2005, luego del XIX Encuentro Nacional de Mujeres, espacio que año a año se desarrolla durante tres días en distintas provincias argentinas, en el que miles de mujeres de todo el país se reúnen para debatir, en talleres horizontales, diversos temas que atraviesan al colectivo, entre ellos, la lucha por la decisión de gestar o no.

Desde su inicio, el apoyo al proyecto de ley de Interrupción Voluntaria del Embarazo sorprendió por su transversalidad, superando las divisiones partidarias para inscribirse como problema de la salud pública, de justicia social, y una deuda de la democracia. El 14 de junio se había logrado ganar, por primera vez en la historia, una media sanción sobre la autonomía de los cuerpos, pero aún restaba la aprobación en la Cámara de Senadores. Es en este lapso de tiempo entre la victoria y lo que vendría posteriormente, se realizó esta entrevista.

\section{DIÁLOGO}

Dora Barrancos: ¿Cómo empezar esta charla? Podrías contarnos la trastienda, el movimiento de instalación del tema y qué pasó a partir del momento en que efectivamente se habilitó la discusión.

Patricia Rosemberg: Sí, podríamos arrancar desde el trabajo que venía realizando La Campaña [Campaña Nacional por el Derecho al Aborto Legal, Seguro y Gratuito], para que no quede que la discusión la habilitó Macri [risas].

Mónica Macha: En realidad, la primera iniciativa fue de La Campaña. Después del 10 de diciembre, fecha de asunción de las nuevas diputadas electas, La Campaña hace una convocatoria como las que venía haciendo siempre, a todas las diputadas y, en general, sucedía que iban solo las asesoras. Cuando se produce el recambio, algunas de las legisladoras que asumimos en diciembre vamos directamente a la convocatoria, y ya eso significó algo distinto.

PR: ¿Fueron varias diputadas de distintos partidos?

MM: Sí, y empezamos a trabajar sobre la idea de hacer nuevamente la presentación del proyecto, con la lógica de La Campaña, que es absolutamente plural ¿no? Se hace esa primera reunión y quedamos en volver a juntarnos. Nos volvemos a juntar en febrero y ya éramos más diputadas, muchas asesoras, y se incorpora también el CELS [Centro de Estudios Legales y Sociales], y algunas organizaciones. 


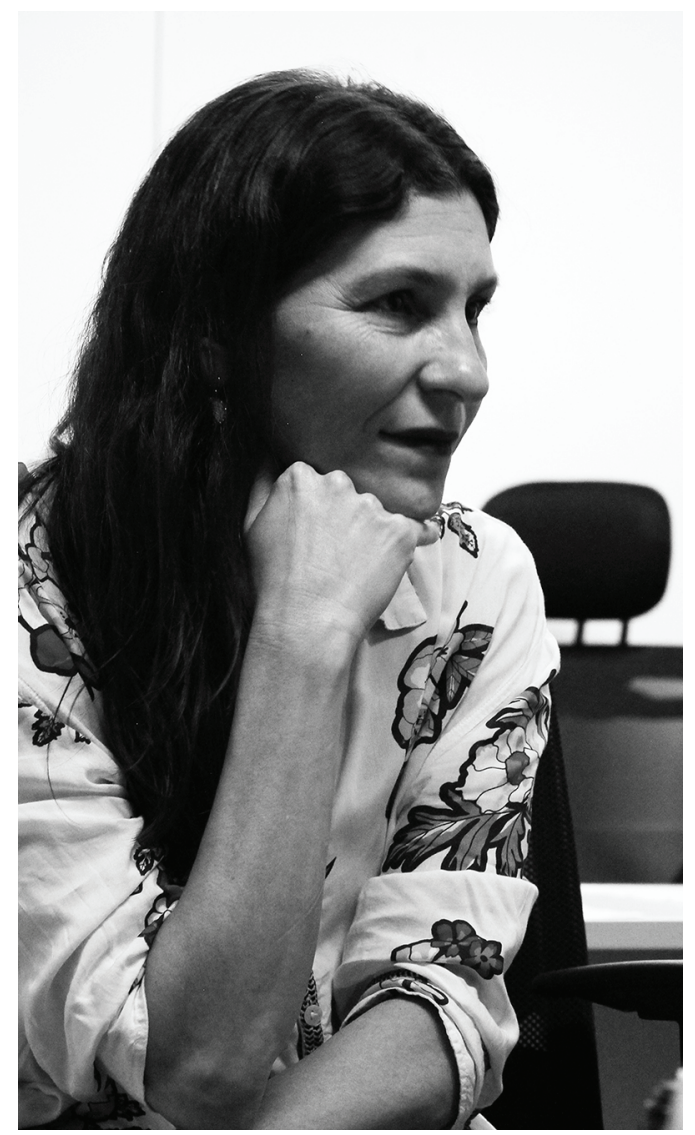

Mónica Macha, diputada nacional, 2018. Foto: Sofia Spinelli.

Dora, vos también viniste a algunas reuniones de cabildeo ¿no?

DB: Fui a la primera, a la de febrero...

MM: Exacto, y ahí empezamos a trabajar la presentación del proyecto, para que se presentara el 6 de marzo, pensamos la fecha buscando...

PR: El día internacional de la mujer...

MM: Claro... La presentación tenía que hacerse una vez que se iniciaran las sesiones ordinarias, después del 1 de marzo y antes del 8 de marzo, para llegar al paro internacional con el proyecto presentado. Eso fue lo primero que hicimos: presentarlo. Más allá de la reglamentación de la legislatura, que indica que el proyecto tiene que tener solo una firmante -que es Vicky Donda-, La Campaña propuso que figuraran cuatro coautoras para todo lo que es la visibilización y la promoción del proyecto y, en ese sentido, se da la representación de cada uno de los bloques políticos. Ahí empieza a construirse esta idea de...

PR: Las presentaciones de los años anteriores ¿siempre habían sido de una única autoría?

MM: No, lo que hacía La Campaña en cada presentación era cambiar de bloque, como para mantener la idea de una discusión plural entre todos los partidos, pero con una sola firma, una sola autora, y así comenzamos, así fue el inicio del tratamiento de proyecto de ley que mantenía las mismas características que el que se había presentado en 2016, porque habían acordado entre todas las organizaciones que conforman La Campaña que, en principio, avanzamos así, que estaba bien así.

DB: Contanos cómo se conformó esa buena estrategia de respetar las firmas, más allá de las cuestiones formales, para que hacia afuera se vislumbrara con claridad, y cómo fue el momento en que se dio la luz verde -si mal no recuerdo, se la dieron a mediados de febrero me parece- para que Lipovetzky armara definitivamente una estrategia interna [hace referencia al diputado nacional Daniel Lipovetzky del partido oficialista Propuesta Republicana Cambiemos, actual presidente de la Comisión de Legislación General].

PR: Eso fue posterior a la presentación me parece...

MM: Claro, eso fue en marzo, cuando se resuelve la junta legislativa, y ahí se define. Lo que pasó fue lo siguiente: nosotras resolvemos presentarlo el 6 de marzo y llamar a una sesión especial para el 8 de marzo...

DB: Exactamente, eso fue.

MM: Pero teníamos muchas posibilidades de que esa sesión especial no se pudiera realizar. 
Nosotras decidimos hacer igual la convocatoria y empezar a hacer ruido, a tomar el recinto, a hacer la sesión, teniendo en cuenta que comenzaba la marcha de $\mathrm{Ni}$ una menos, que empezaba el paro internacional de mujeres. En ese contexto, el oficialismo plantea un acuerdo: no hacer la sesión especial a cambio de -y ahí viene el cambio- trabajar el tema en plenario de comisiones, no en cada una, y después en otra y otra y otra, sino trabajar en plenario de las cuatro comisiones por las que tenía que pasar el proyecto y que se tratara antes del mundial de fútbol, de ahí la fecha del 13 de junio, que era la fecha límite para el tratamiento en el recinto. Suponíamos que, con el mundial, todos los demás debates se iban a caer, entonces llegamos a esos dos acuerdos: plenario de comisiones y $13 \mathrm{de}$ junio como fecha para tratar en el recinto. En ese lapso, entre el momento en que comenzamos a trabajar en el plenario hasta el 13 de junio, acordamos que se iban a realizar las reuniones informativas, y que esas reuniones iban a tener un reglamento, o sea, que en la primera reunión de plenario de comisiones se iba a establecer el propio reglamento de funcionamiento de las reuniones informativas. Eso fue a fines de marzo, me parece, y ya después comenzamos en abril y mayo con las reuniones informativas.

PR: ¿Y cómo fue el entramado dentro del Congreso? Me Ilama mucho la atención la transversalidad del proyecto, con diputadas de distintos bloques, y la situación no centrada solo en la votación, sino en los discursos, algunos discursos en la cámara que no fueron vislumbrados por los partidos ¿no?

DB: La sensación es que fue sorprendente para Cambiemos...

PR: Sí, claro.

DB: Y creo que esa sorpresa expresa una huella dura de lo que todavía existe $y$, en ese sentido ¿cómo fue el primer armazón de quienes estaban a favor y en contra dentro de Cambiemos?
MM: Hay un primer corte del interbloque Cambiemos por parte de las diputadas que vienen del radicalismo, las radicales históricas en la pelea por el aborto legal, con María Luisa Storani a la cabeza. Aunque María Luisa no esté como diputada, ella se encargó de nuclear, sobre todo, a las mujeres radicales. Ahí había dos trabajos en simultáneo: por un lado, construir la transversalidad entre nosotras y nosotros $y$, por otro, definir explícitamente la necesidad de dejar por fuera otras discusiones, de no chicanearnos, es decir, si no dejábamos en suspenso las diferencias que teníamos en otros temas, no íbamos a poder avanzar en el tratamiento de la legalización del aborto. Estábamos convencidas que queríamos eso y de hecho lo intentamos cada vez que hablamos, sobre

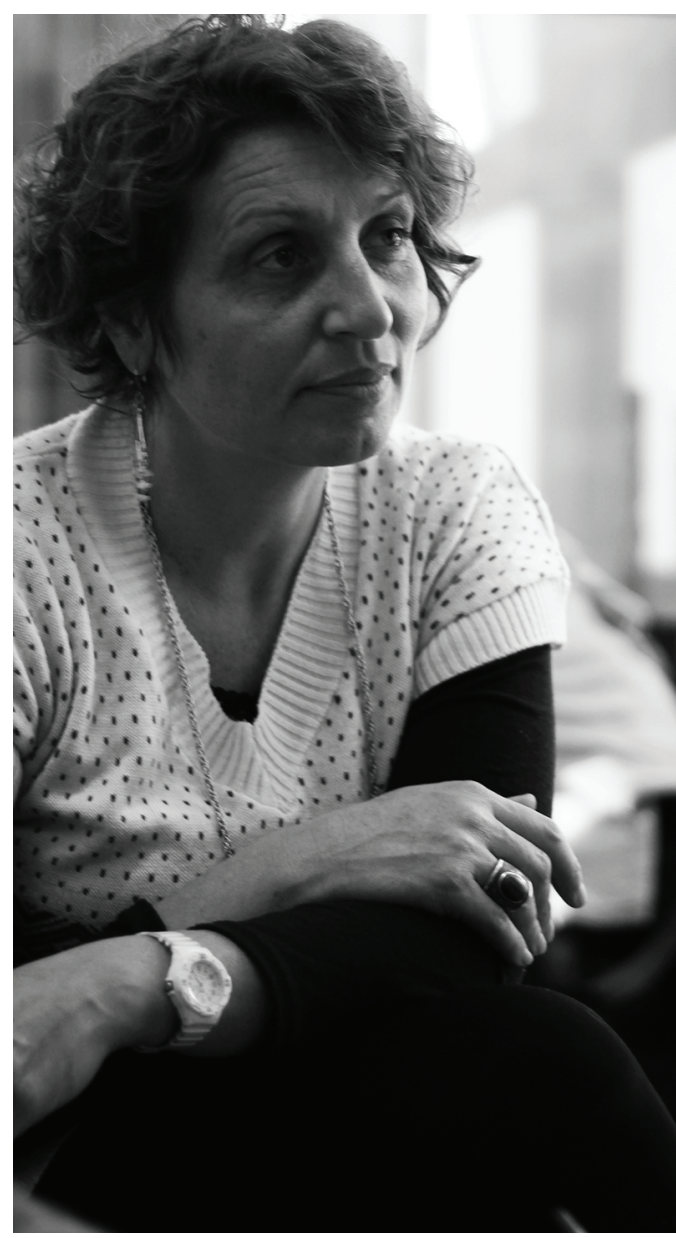

Patricia Rosemberg, ex directora de la Maternidad de Moreno Estela de Carlotto, 2018 Foto: Sofia Spinelli. 
todo, cuando hablamos de aborto. Después se daba toda la discusión política, obviamente, con todo lo que está pasando, pero cuando hablábamos de aborto, y cuando estábamos trabajando con el tema de la legalización del aborto, era solamente ese tema, y en eso coincidimos y en eso sabíamos que teníamos que tener una estrategia entre nosotras y hacia afuera, y cada uno y cada una hacia adentro en los bloques también. Ahí fue cuando empezamos a construir dentro del Frente para la Victoria (FPV) la idea de poder ir consolidando los votos a favor, ahí había una primera cuestión que también plantea Agustín Rossi como presidente de bloque: "yo voy a votar a favor, estoy de acuerdo, pero no voy a hacer ninguna declaración, ni voy a firmar ningún proyecto, ni voy a plantear esto en los medios de comunicación, ni nada", para respetar la situación del bloque que tenía 54 votos a favor de la legalización, en ese momento tendríamos ocho en contra y dos que estaban dudosos y que finalmente terminaron votando en contra. Mayra [Mendoza] y yo nos encargamos de todo el trabajo adentro del bloque, y fuimos logrando juntar esos votos a favor. Cada diputado y disputada tenía la posibilidad de invitar a cuatro personas para las reuniones informativas, pero alguno te decía: "a vos te cuento que voy a votar a favor, pero no quiero ni que se entere nadie, ni nada, te dejo los cuatro lugares, no quiero saber, no me quiero involucrar mucho, pero voy a votar a favor", y había otros que se comprometían, que estaban y querían que venga tal o cual de la provincia $¿$ no? hubo ahí una diversidad importante. Implicaba, por un lado, una cuestión de cuidado hacia adentro del bloque y que esa tensión no rompiera el bloque, porque también estaba ese temor.

DB: Gran número de varones en el bloque.

MM: Sí, exactamente.

DB: Pero hay una cuestión que es notable, el $50 \%$ de las mujeres votó en contra.
MM: Sí, exactamente.

PR: Del total de las diputadas de todos los partidos, el $50 \%$ votó en contra.

DB: ¿Cómo ves esto? Porque es una marca grave ¿no? Ni la Ley de Identidad de Género, ni la Ley de Matrimonio Igualitario tuvieron un porcentaje mayor de mujeres votando en contra.

MM: Me parece que no tienen una mirada feminista, ni del derecho de las mujeres sobre el propio cuerpo, o sea, son mujeres, pero son patriarcales a la hora de pensar en esta temática y además hay cierto prejuicio respecto de lo que pasa en las provincias...

DB: ¿ Te sorprendieron algunas de las mujeres del bloque que votaran en contra?

MM: No, no.

DB: ¿No hubo sorpresas?

MM: No hubo sorpresas, pero porque hay mucha relación y mucho espacio de conversación, entonces las que votaron, estoy pensando en todas las que votaron en contra de nuestro bloque, ya lo venían planteando...

PR: Me imagino que también el cambio implicó mucha conversación ¿no? Porque más allá de las mujeres y los varones que tenían alguna lectura con relación al aborto ¿cómo es la construcción de quien va cambiando de opinión? No de quien tiene el no marcado, sino de quien a lo mejor es un no que después se va transformando y vota que sí. ¿Cuánto de esto pudieron trabajar como decisión individual y cuánto como decisión representacional de diputados? Desde afuera, me llamaba mucho la atención, por un lado, que alguien hable desde sí mismo, sin poder correrse nunca de lo que representa, de quienes lo votaron $y$, por otro lado, esto que dice Dora también, de si el voto negativo, es un voto con la convicción de que no se debe legalizar el aborto, o desde la fantasía de que en las provincia opinan tal o cual cosa, 
cuando no sabemos qué es realmente lo que opinan en las provincias.

MM: Sí, una de las diputadas me decía que era su convicción, y no era como en otros casos en los que podían plantear que en la provincia le decían tal cosa, ella no. De hecho, tuvimos otra diputada que en principio iba a votar que no, después iba a votar que sí, porque la hija le decía: "no entras más a casa, si votas en contra, no sos más mi madre", le escracharon la casa y terminó votando en contra. Es decir, fue y vino.

PR: Por eso me impacta el rol del diputado, del dirigente político. Ayer uno de los senadores decía que su fuerte convicción era una hija de 17 años, me impacta, una hija de 17 años con el aliento en la nuca.

MM: Un diputado estaba a punto de votar en contra y decía: "yo no quiero tener diferencias con el papa", pero él lo decía, todo esto off de récord [risas].

DB: Así explícito, él dijo no quiero...

MM: Pero después la hija le machacó tanto, tanto, tanto, que también terminó votando a favor, porque prefirió tener diferencias con el papa [risas] y no con la hija.

PR: Obvio, al papa no lo ve todos los días, está más que claro. Y en los otros ¿cómo fue este proceso? Para modificar las opiniones de otros compañeros de bloque ¿cuánto jugó el vínculo personal en el cambio de idea y cuánto la representación institucional de tener la oportunidad histórica de votar la ley? Porque hubo muchos que del no pasaron al sí, y esto tuvo que ver, creo, bastante menos con las disertaciones y bastante más con el trabajo.

DB: Con la marea.

MM: Creo que el tema tiene su impacto sobre todo en los más jóvenes, en los varones más jóvenes. Lo que se viene viviendo, por lo menos desde 2015 hasta acá, con las marchas de Ni una menos y demás, tiene su impacto.
De hecho, ingresé a la cámara a principios de diciembre del año pasado, y venia como con el sello puesto de feminista... Y empezó a pasar, como en muchos otros lugares, que cuando entraba a las reuniones, decían: "ojo que acá esos chistes no se pueden decir". Hay algo que comenzó a pasar entre ellos, empiezan a incomodarse por cosas que antes las tenían muy naturalizadas, desde los chistes, los comentarios, los insultos, todas esas cosas que empiezan como a resquebrajarse y creo que, en esa línea, también terminan revisando su posición con relación a la legalización del aborto. Porque hay muchos varones jóvenes, que son de otras provincias, pero que tienen una formación católica importante, que vienen de la UCA [Universidad Católica Argentina] o de la Universidad del Salvador. Sin embargo, fueron haciendo también una reflexión.

DB: Volviendo a la transversalidad: ¿cómo fue la jornada del 13 de junio?

MM: Estuvimos todo el día conversando entre nosotras y con los diputados y diputadas que aún no tenían su voto definido. Al final pedimos una reunión con Monzó, en su carácter de presidente de la cámara. Todas... Tuvimos una reunión con él a las siete de la mañana del 14 de junio. A esa hora estábamos perdiendo, entonces fuimos con un grupo de diputadas a pedirle una reunión a Monzó. A la noche había decaído un poco la vigilia, y empezamos a pedirle a todo el mundo que volviera: "vuelvan, necesitamos gente", "necesitamos presión porque estamos perdiendo". También trabajamos en una estrategia con la prensa, con algunos actores claves que empezaron a twittear, fue todo un armado conjunto "pongamos este twitt", "bueno, sí, vamos por acá"; las actrices, Dolores Fonzi que se paró y se quedó ahí clavada twitteando... El tema de las redes también fue muy importante, y en esa reunión que tenemos con Monzó le decimos: "están Ilegando más mujeres, van a venir, estamos perdiendo y nosotros no controlamos a las compañeras que vienen".

DB: Perdón, pero ¿cuál era la evidencia de que estábamos perdiendo? 
MM: Estábamos contando votos. Estuvimos toda la noche sentándonos al lado de uno, de otro, tratando de convencer e ir viendo y, cada tanto, hacíamos un registro, un recuento de cómo estábamos en general.

PR: En ese momento teníamos a los de la provincia de La Pampa en contra.

MM: Exacto, teníamos algunos que habían dicho que votaban a favor y que a último momento se dieron vuelta, entonces sabíamos que podíamos perder por dos o tres votos. Entonces le pedimos esa reunión a Monzó y le dijimos: "van a volver todas las mujeres que estaban a la noche en la plaza, más las pibas que no van a ir a la escuela y van a venir para acá con el pañuelo verde".

DB: ¿Eso le dijiste a Monzó?

MM: Sí, eso le dijimos entre todas.

PR: Eso fueron las sororas, no el interbloque.

MM: Y les dijimos que no las podíamos contener, porque nosotras podíamos responder por grupitos de cien o doscientas compañeras que son las que responden a nuestras agrupaciones. Pero esto no eran agrupaciones, eran chicas organizadas que venían pero que no respondían a ninguna agrupación...

PR: Organizadas y no organizadas ¿no? Porque la calle era una marea verde.

\section{DB: ¡Un hormiguero!}

MM: Nosotras le dijimos: "tiene que intervenir Macri", "que defina el presidente". Pretendíamos Ilegar a un escenario de empate. Y mientras estábamos avanzando en esa línea, volvemos al recinto y vemos el twitt del gobernador Carlos Verna diciendo que sus diputados iban a votar a favor ¡listo!

PR: Todos vamos a ir a La Pampa eternamente de vacaciones, no importa. De aquí al fin de los días vamos a ir a La Pampa [risas].

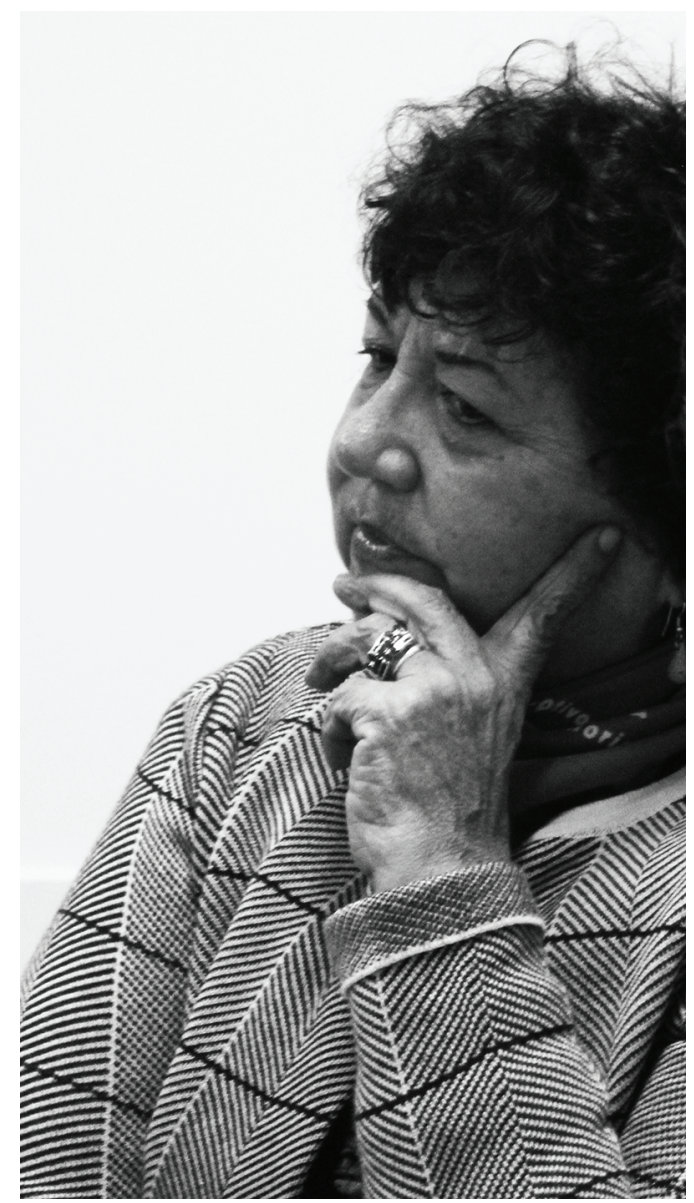

Dora Barrancos, ex directora, Instituto Interdisciplinario de Estudios de Género, Facultad de Filosofía y Letras, Universidad de Buenos Aires, 2018.

Foto: Sofia Spinelli.

DB: Yo soy pampeana... y el día anterior, me Ilama una chica que es conductora de un canal bastante importante, pero me llamó cuando estaba en el directorio y no sabía que salía directo a la tv, que era una voz en off, y entonces ella me dice: "Dora acá estamos con el problema de los pampeanos", y ahí me dije "ah no, yo voy a hacer un alegato": "iLa Pampa, la primera provincia que tuvo Ley de Salud Sexual y Reproductiva!, ¡La Pampa!, no sé qué cosa". A la noche, me hizo tanta gracia porque Felicita me dijo "lo conseguimos". No, lo consiguió obviamente Verna. Lo que me parece importante es que efectivamente ahí se metió la política grande, por el enojo de Verna con el presidente... 
PR: Es que Macri tenía una responsabilidad institucional, por ser presidente, de evitar lo que iba a pasar. Porque, además, después pasa a la Cámara de Senadores, con lo cual para seguir operando en contra de la ley tienen tiempo posterior. Aunque esa parece ser la lógica de la política de Cambiemos ¿no? No sé si es no medir o también cómo esto puede ser usado para desprestigiar al feminismo a las mujeres, al FPV ¿no? Me parece que eso también era un escenario que ellos aprovechan.

\section{MM: Exacto.}

DB: Ahora, hubo discursos efectivamente lastimosos ¿no? Además de la muchacha de la metáfora canina, el representante de Tucumán... que es un personaje muy, muy particular, que dijo cosas tremendas.

PR: El que dijo lo de la dictadura y amenazó a Cabandié.

DB: Hubo tanto exceso ¿no? Bajaba tanto la propia categorización representante, lo que se vio es que había mucha, mucha resaca de representación.

MM: Sí, totalmente. Creo que algo que mostraba la cámara era que no estaba siendo una fiel representante de lo que estaba sucediendo socialmente. En la sociedad hay una mayoría que está a favor de la legalización y esa mayoría costó mucho construirla en Diputados, y va a costar mucho construirla también en el Senado, porque ahí hay -como vos decís- una resaca de algo que va quedando, además, con discursos que se emparentan mucho. Como lo que dijo uno de los diputados con relación a los que tenían pañuelos verdes y hablaban de la ESMA "si las mujeres que parieron allí hubieran abortado varios diputados que están acá no estarían".

PR: Muy amenazante...

MM: Claro, muy fuerte, o Massot diciendo "ni nosotros nos animamos a tanto".
PR: Creo que, por un lado, hay una gran mayoría de la población a favor de la legalización que no se refleja en las cámaras legislativas; pero, además, en el Senado hubo discursos como el de esta mujer diciendo "¿qué pasa cuando una perrita queda embarazada?", que planteaba a la mujer en su condición de hembra reproductiva, que son peores que los discursos más antiderechos que se escucharon en la cámara de diputados, que tienen una base, la mayoría religiosa. Ahora ¿cuánto permea en las cámaras legislativas el proceso que se dio afuera? Igual creo que suma para todos lados, porque lo que suma es ponerlo en instancia pública; lo que pasó con todas esas mujeres y muchos varones también en esa vigilia, eso hizo los discursos, no la trasmisión. Creo que hubo un fenómeno que también tiene que ver con el recambio generacional de las diputadas y los diputados, que es el uso de las redes y los medios de comunicación y cómo todos aprendimos a tener un discurso que permee por algún lado, inclusivo los que disertábamos con menos figuras.

MM: Definimos estrategias, encaremos el tema desde la salud pública, la justicia social...

PR: Y eso también me parece que es una construcción muy interesante, porque cuando ustedes dijeron "vamos por salud pública y justicia social", nosotros nos alineamos todos rápidamente, somos esquemáticos, "este es un problema de salud pública, contemos cuántas mujeres se mueren y cuántas..." aunque en el fondo esté todo el otro trasfondo de lo que pensamos también con relación a esto, pero esa alineación de discursos también me parece que es una construcción política desde La Campaña, que es muy interesante, que se da porque hay un recambio, porque hay otras posibilidades de disputar, porque también pudimos ampliar la mirada a lo que era más necesario.

MM: Creo también que La Campaña tiene toda una trayectoria de todos los años de construcción política y de meter el tema incesantemente, y creo que hay un plus que le da 


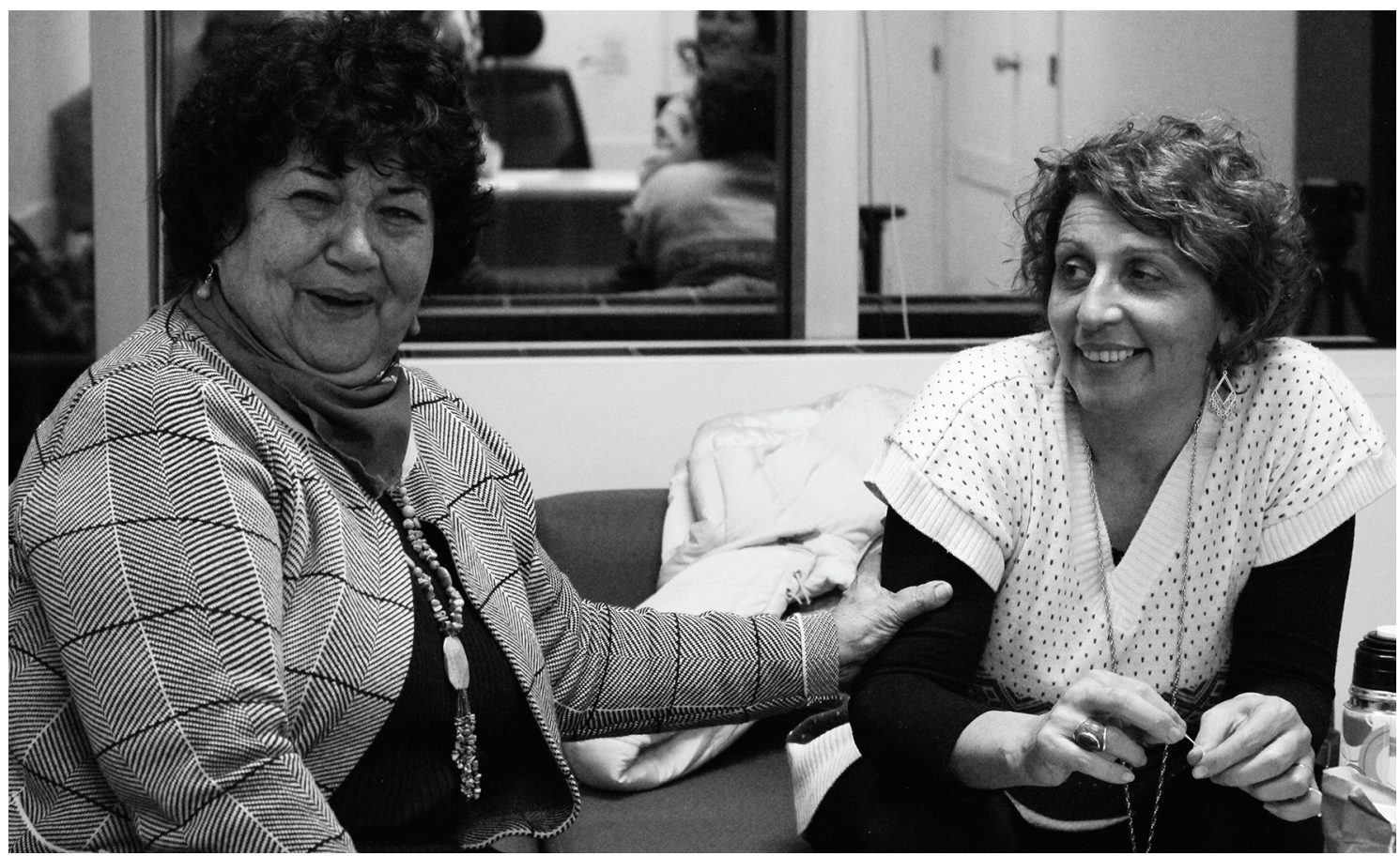

Dora Barrancos y Patricia Rosemberg, 2018. Foto: Sofia Spinelli.

el Ni una menos, que son como dos mundos que también tienen sus tensiones. Yo creo que Ni una menos le da toda la cuestión comunicacional muy fuerte. De hecho, muchas son comunicadoras sociales que se metieron en los medios de comunicación. El otro día jodíamos con que deberíamos hacer cosas con "gracias Facundo", porque Facundo Arana con esto de decirle a Isabel Macedo, que ahora que estaba embarazada se realizó como mujer, fue el inicio, y ahí empieza a meterse el tema y la discusión seria del aborto en los programas de televisión de la tarde.

PR: Totalmente, Señorita Bimbo en el programa de Rial.

DB: Y después de la extraordinaria jornada, dentro del bloque, aquellos que no votaron a favor no la pasaron del todo mal. Me imagino que ustedes han hecho estratégicas alianzas, por las dudas, por si el proyecto vuelve, digamos porque ahí está la cuestión.
MM: Creo que, si el proyecto volviera a diputados, el grueso de los votos los vamos a mantener, hay cosas que se dieron en ese momento y que sería más dudoso que podamos repetirlas. Nosotras hicimos una militancia, nadie se podía ir, todos tenían que estar. Si es necesario habrá que volver a hacerla, se volverá a hacer.

PR: Porque está implícito votar en contra. La idea es que no salga la ley, no era su voto el que les preocupaba. Lo que les preocupaba era que nos saliera la ley. ¿Qué otras cosas más profundas están ahí?

DB: En el Frente Renovador igual hubo algunos casos muy interesantes, pero siempre me impacta el oxímoron, por tantas razones que es doña Graciela Camaño.

PR: A mí me impactó mucho Camaño.

DB: Ahora ¿Se puede explicar por qué? Porque me imagino, y lo digo con deliberada in- 
tención, que es de esas personas que efectivamente ha experimentado de cerca y de lejos el aborto, esto no me cabe la menor duda. Entonces, de dónde le viene la...

MM: La vehemencia para votar en contra...

DB: ...para votar en contra. Una cosa es que vos no votes, otra es que te repliegues, otra es que hagas un discurso encendido.

PR: Como jefa del bloque, además, digamos eso...

DB: Como jefa del bloque.

PR: Eso también me impacto, los jefes de bloque. $Y$ retomando una pregunta anterior ¿qué se juega en cada representación? También el jefe de bloque que tiene la voz del bloque, con un bloque que vota dividido, porque para el presidente del bloque de la izquierda estaba más claro, era más fácil, todos votan a favor. Ahora Camaño, con un bloque dividido...

MM: Camaño igual habló en representación de la parte del bloque que votaba en contra. Ellos también votaron divididos.

PR: Pero como jefa de un bloque ¿cómo es que habla por sí misma o por parte del bloque?

MM: La verdad es que no la conozco tanto a Camaño. Sé lo que se conoce públicamente. Sí sé que fue una militante en contra permanente.

DB: ¿No tenés la impresión de que ese tipo de diferenciaciones, de divergencias, son muchas más duras y hostiles que los fondos buitres? Con los fondos buitres vos podés estar en contra, pero en estos temas, estas gestiones, tienen una profundidad que hace que la pulsión de la enemistad, o de la amistad, se profundicen. Nunca me voy a olvidar el quiebre del FrePaSo [Frente País Solidario], es cierto que tenían cosas muy malas. Yo era diputada en la ciudad, y se discutía el tema de la prostitución en el artículo 71 del Código de Convivencia, y lograron que se aprobaran las detenciones y la intervención policial, y eso fue muy duro. Con mucha gente obviamente después se reanudó el vínculo, pero fue una herida profunda.

PR: En el caso de la sesión por la legalización del aborto ¿qué paso después?

MM: Creo que nosotras no llegamos a un nivel de enemistad con nadie. Lo que para muchos es un temor, para mí no porque estoy adentro, no lo siento como un temor. Pero si es al revés ¿cómo lográs juntar personas muy diferentes en un vínculo más humano?

PR: La imagen de ustedes saliendo con Mayra [Mendoza], con Silvia Lospennato, con Vicky [Victoria Donda], fue muy impactante, porque habla del entramado, del entretejido, es muy impactante para el sentido común.

MM: Además salimos, como diciendo "salgamos a la calle", "estamos acá". Hubo un momento en el recinto en el que vimos que podíamos irnos, porque también está eso, de que si llaman a votar y no estás y todas estas cuestiones, y elegimos ese momento para salir, hacer un saludo, pedirle a la gente que se quede y volver rápido al recinto. $Y$ eso también generó algo. Sé que las diferencias políticas que tengo con Brenda Austin, con Silvia Lospennato, las voy a tener y vamos a discutir siempre. No cambiaría de ningún modo la mirada política sobre los temas, pero a veces hay discusiones en el recinto que son... para las piñas, hay una cosa también que me parece que es muy de la construcción y la lógica de disputa política de los varones.

PR: Sí, de los varones, me parece que esa cosa de chicaneo, chicaneo, chicaneo, es de una cosa más masculina ¿no? Otra cuestión es que esa transversalidad habla de otra posibilidad de participación política para la ciudadanía. El hecho de que alguna causa nuclee más allá de mantener diferencias políticas profundas, también habla de una posibilidad de construcción, como las cuestiones de género, las mujeres $y$, sobre todo, las adolescentes, que esa noche de vigilia eran el sub17. Yo 
escuchaba en esos días el pasaje del "que se vayan todos", al "que vengan todas".

MM: Totalmente. Algo que estaba pensando con relación a cómo convivir con la discusión por la legalización del aborto y todos los otros temas que son muy complejos. En ese sentido, lo que sí me pasó fue que en uno de los martes verdes venía Miss Bolivia. Daniel Grinbank fue un jugador tremendo, impresionante, puso el escenario, todo, $y$, además, llamaba a distintos diputados. Un día se hizo un recital acá, después del 13 de junio, y la idea era que venían Griselda Siciliani y otras actrices y músicas argentinas a cantar, porque la propuesta era mostrar que nosotras militábamos alegremente, que estábamos peleando por un derecho. Pero fue el mismo día que se echó a la gente de Télam [la agencia nacional de noticias], el día de los 350 despidos, entonces yo estuve ahí un rato y luego me fui porque era un límite; no podemos estar arriba de un escenario cantando, aunque el motivo sea el mejor del mundo, el mismo día que echaron a 350 personas de Télam...

DB: No podés estar en jolgorio ahí...

PR: Claro, no. Bueno eso también está buenísimo, es muy importante.

DB: Claro, digamos que la causa no iba a perder porque no estés.

MM: No, no.

PR: Tal cual, no era la votación, era el escenario, y eso también me parece que habla... Otro tema es la reacción que devino con posterioridad desde los sectores antiderechos...

DB: Es una reacción que me parece todavía muy de la enjundia obispal. Llegué a Paraná un día y veo una gran cantidad de gente, y pregunté "qué es esto" y se trataba de una movilización de los antiderechos, con mucha gente, de muchos lugares, pero no vi la misma capacidad de movilización que, por ejemplo, hubo contra el matrimonio igualitario, con las iglesias, las neocristianas, las más nuevas...
PR: Sí, las evangélicas...

DB: Las evangélicas, ustedes recuerdan que hicieron una cosa tremenda, trajeron a todo el mundo. Mi conjetura es que la enorme movilización que hicieron las iglesias evangélicas contra el matrimonio igualitario, no la hicieron ahora. Es decir, no hay estridencia en la oposición, hay voces terribles, voces que se manifiestan, pero nunca pasan de ¿200 personas?

MM: Con suerte.

DB: Eso no tiene nada que ver con la movilización que vimos, por ejemplo, con relación al matrimonio igualitario, me refiero a esos grupos. Hay algo raro y la verdad que deberíamos investigar un poco...

PR: A mí lo que me impacta es el nivel de violencia del sector salud en contra de la legalización. Está claro que después hay que ver en el zarandeo cuántos son, pero el sistema de salud tiene muchas cosas violentas, y muchas cosas violentas naturalizadas. Por ejemplo, la explicitación de la violencia de los médicos de La Rioja que dicen: "en mi guardia los abortos se van a hacer sin anestesia". Ayer a mí me tocó disertar con un médico, un urólogo, jefe del CEMIC [Centro de Educación Médica e Investigaciones Clínicas "Norberto Quirno"] con un discurso nazifascista, con mentiras permanentes, haciendo uso de construcciones como "usted señora, que tiene un cáncer de mama, le quiero decir que no la vamos a poder atender porque vamos a estar atendiendo a mujeres que, por no cuidarse, se vienen a hacer un aborto". Tremendo. De todos modos, lo cuestionaron hasta los propios senadores. Miguel Ángel Pichetto le preguntó "¿cuántos médicos hay en la República Argentina?, dígame por favor cuál es la entidad que los nuclea a todos, que yo quiero sentarme con esa entidad que nuclea a los 800.000 médicos y se terminó". Como la frase "no cuentes conmigo...". Lo simbólico de esas frases me preocupan. 
DB: Yo tengo una conjetura que, en realidad, hay que trabajarla más, y que tiene mucho que ver con el plano de la salud: ¿por qué los médicos aparecen en este planteo? Obviamente convocados por el tema central de salud pública. Pero creo que ahí hay una interpelación, que origina esos estándares en sintonía y en epidemias de objeción, que no tiene nada que ver con la religión, porque ese grupo de profesionales ¿es más religioso, que,

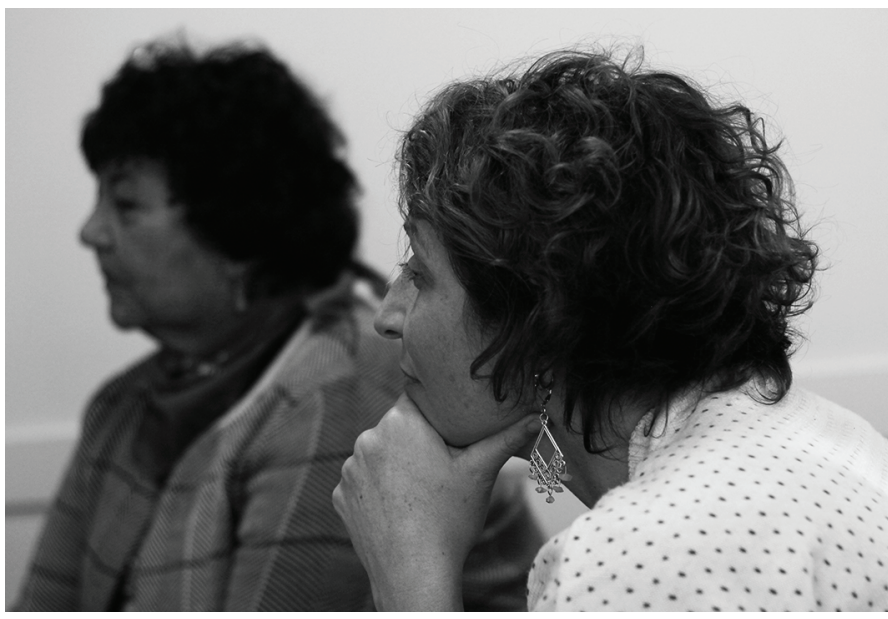

Dora Barrancos y Patricia Rosemberg, 2018. Foto: Sofia Spinelli. por ejemplo, los abogados? Me parece que el problema es de otro orden. ¿Cómo vos vas a decidir hacerte un aborto?, tu cuerpo le pertenece, en realidad, al orden médico. $\mathrm{Y}$ ahí hay una estructura muy patriarcal, que tiene todos los indicios decimonónicos, con una cuestión de falsete moral: "esta me viene a joder con aborto", o " ¡hey! cerrá las piernas" que son los comentarios triviales, pero que en realidad manifiestan una puja: si nosotras tomamos decisiones sobre nuestros cuerpos, son menos cuerpos de ellos.

PR: Totalmente.

MM: Absolutamente.

DB: Son menos cuerpos de ellos, y esto para mí es una cuestión que hay que indagarla, porque no tiene nada que ver con la configuración religiosa o filosófica.

MM: Es una cuestión de poder.

PR: De poder sobre el cuerpo.

DB: De poder sobre el cuerpo y ahí hay una lesión, una lesión a la potestad...

PR: Cuando trabajamos con la objeción de conciencia es desde la humildad, del conflicto, yo digo "mirá, si vos sos objetor de conciencia lo tenés que hacer con humildad".

Lo que no podemos hacer es salir a hacer una cacería de objetores, una lista de objetores, ¿a quién se le puede ocurrir salir a hacer una lista de objetores de conciencia? Pero, además, creo que si la objeción de conciencia la ponemos en valor, es decir, que tenga un valor negativo ser un objetor de conciencia, se termina, si se le hiere esa omnipotencia... A lo mejor porque estoy con eso todo el tiempo y todos los días me preocupa la violencia...

DB: ¿Y la objeción?

PR: No, con la objeción que hagan lo que quieran... la práctica me da preocupación. ¿Por qué se incluyó la penalización para la mujer que se realiza un aborto a partir de la semana 15? Esta posibilidad de penalización ¿no excluye la posibilidad de causales con la consiguiente traba en los equipos de salud?

MM: La penalización se pone porque, según los abogados y las abogadas, el riesgo es que de no estar planteada una pena, se pueda declarar la inconstitucionalidad de la ley.

DB: Ayer escuchaba a Claudia Piñero, que decía que después de sus manifestaciones había recibido un feroz ataque en las redes. Es cierto, yo no tengo ni Facebook ni Twitter y me libero muchísimo... me privo de los 


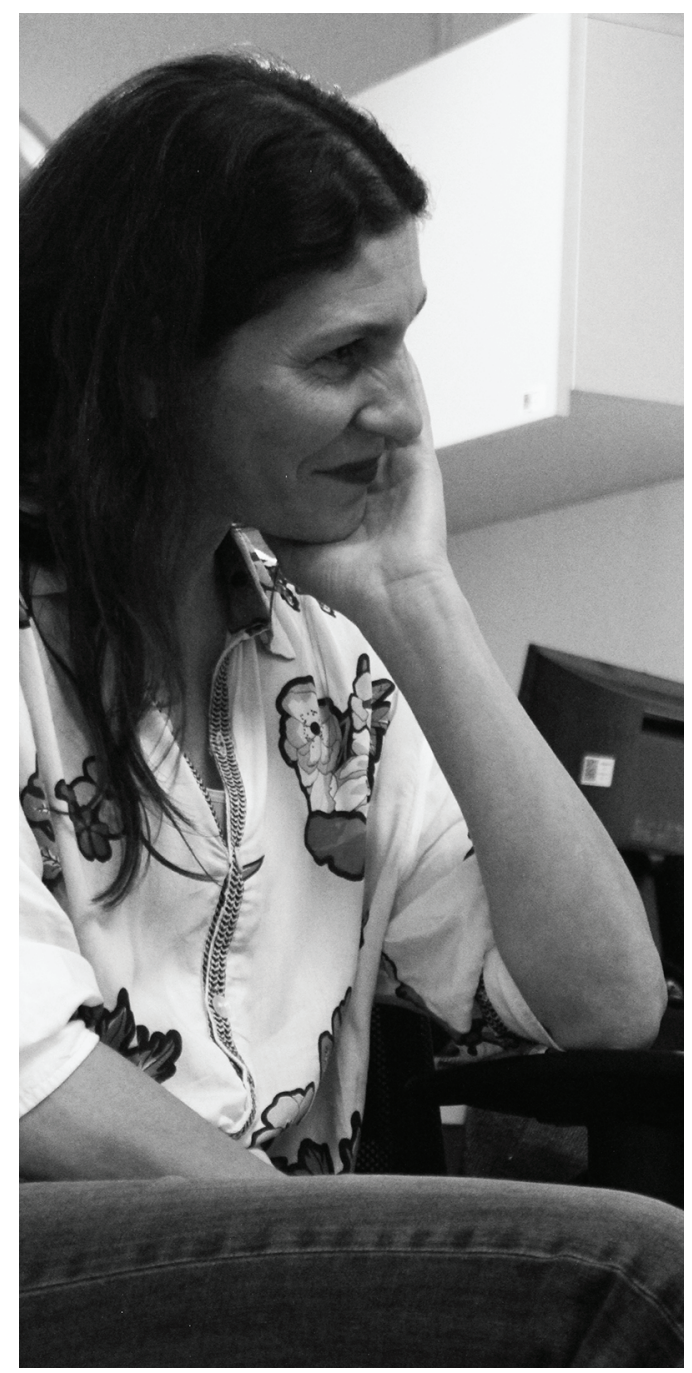

Mónica Macha, diputada nacional, 2018. Foto: Sofia Spinelli. calle, no se animan a armar la movilización, no pueden armarla, no pueden llenar la Plaza del Congreso...

MM: No.

PR: Fijate lo que pasó con la convocatoria de los antiderechos en Ferro, también porque estar anti-algo, siempre es un motivo difícil para movilizarse.

MM: Pero creo que hay algo de la movilización que también está más acotada, si no hay videítos y cositas diciendo que va a haber micros, va a haber esto y va a haber aquello...

PR: La gente no se moviliza... También vuelvo con la adolescencia y la juventud esto de "la revolución de las hijas", esto tiene un peso muy fuerte, muy impresionante.

DB: Yo tengo ahí una hipótesis y una pregunta ¿cómo devino esto? ¿cómo devino esto en nuestras narices? Yo creo que tiene muchísimo que ver, desde luego, el contexto. Con los grados de significación del contexto, con la franquía para la sexualidad, la gente no retrocede... Esas adolescentes que hacen sus experiencias de un lado y del otro no quieren retroceder, no retroceden "conmigo no va a pasar" dicen las pibas, "a mí no me vas a tener en el closet por eso". Me parece que está por ahí todo el otro cauce...

PR: El disfrute del goce...

DB: Sin la revuelta de la sexualidad, no hubiera devenido todo esto.

MM: Y yo veo mucho de ese efecto de la Ley de Matrimonio Igualitario y de Identidad de Género.

PR: De poder hablar del goce, de poder hablar de la sexualidad.

DB: Eso me parece extraordinario, eso es lo que no retrocede. En mi época pensábamos que estaba lo principal y lo secundario, y hoy hemos podido poner estas cuestiones 
en valor, con el mismo valor que la cuestión política y eso me parece que las jóvenes lo han aprendido rápidamente.

MM: Totalmente.

PR: Sí, claro, y porque además no hay marcha atrás después de eso. De la sexualidad y del goce no hay marcha atrás.
DB: No hay marcha atrás.

MM: Y, además, más allá de lo que pase el 8 de agosto, si no sale la ley el 8 de agosto, saldrá en otro momento...

DB: Como yo digo: iya ganamos!, ¡ya ganamos!

\section{FORMA DE CITAR}

Barrancos D, Rosemberg P. Aborto, sororidad y autonomía de los cuerpos: diálogo con la diputada nacional Mónica Macha. Salud Colectiva. 2018;14(3):447-460. doi: 10.18294/sc.2018.2006.

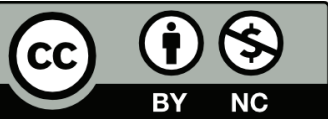

Este obra está bajo una licencia de Creative Commons Reconocimiento-NoComercial 4.0 Internacional. Reconocimiento - Permite copiar, distribuir y comunicar públicamente la obra. A cambio, se debe reconocer y citar al autor original. No Comercial - Esta obra no puede ser utilizada con finalidades comerciales, a menos que se obtenga el permiso. 